\title{
Librarians' Personal Web Pages: An Analysis
}

\section{Annette Haines}

An e-mail survey and an investigation were made of academic librarians' personal Web pages in order to understand what role they play in the organization of the Internet. Subjects were selected from two Internet lists of librarian's Web pages. Results showed that most Web sites were produced voluntarily and serve multiple purposes. An independent t-test determined that those librarians who were provided with guidelines produced higher-quality Web pages. Guideline effectiveness and suggestions for further research are discussed.

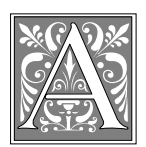

well-developed sense of organization, knowledge of search strategies, and understanding of hierarchies serve librarians well as they increasingly integrate the World Wide Web into research and information services. Taking on the additional role of Internet specialist, librarians are exploring the possibilities of this virtual world in many ways. Most notably, librarians are actually giving shape to the Web itself as Web page designers. Librarians have not only worked at developing library home pages, but they also have contributed their own identities to the Web by creating personal Web pages.

\section{Research Goals and Objectives}

This study was conducted to investigate the role academic librarians' personal Web pages play in the organization of the Internet. Specifically, why do librarians produce personal Web pages, what do these sites look like, and what type of help and support did the librarians receive along the way?
The information presented in this study will benefit librarians just beginning to create their personal Web sites as well as those with established sites. In their research article on library Web design, Mark Stover and Steven D. Zink discussed the need for librarians to attain competence as Web designers. According to the researchers, "The organizational expertise and abilities required to transfer information skillfully to a broad audience through library Web pages is one visible way that librarians could showcase their potential role in the emerging information age. To date, the effort has been largely disappointing." ${ }^{1}$ By looking at what others have done well, and perhaps not so well, librarians can discover new ideas and learn how to improve the design and content of their own Web pages. The data collected will also aid administrators in understanding their role in providing training and guidelines for librarians' personal Web pages. 


\section{Related Research}

\section{The Sociological Role of Personal Web \\ Pages}

Currently, no literature directly addresses librarians' personal Web pages. However, Marcia J. Bates and Shaojun Lu assessed personal Web pages in general. ${ }^{2}$

Although many of the personal Web pages had features in common, they exhibited much variety in both purpose and content.

They profiled the structure, content, and design characteristics of typical personal Web pages selected systematically from a Web page directory located on the Internet to determine what sociological role these pages fulfilled. Approximately two-thirds of the sites studied served a work-related purpose such as a resume, a performance announcement, or a product advertisement. Twenty-nine percent seemed to have no purpose other than to show the site-creator's ability to design a Web page. Three basic types of pages were identified: a simple contents menu of links to other pages with no extraneous text; straight text with few links; and many links with a menu or contents at the beginning of the page. Although many of the personal Web pages had features in common, they exhibited much variety in both purpose and content. Thus, the authors concluded that the social form of the personal Web page was still taking shape.

\section{Characteristics of College and University Library Home Pages}

To gain an understanding of academic librarians' personal Web pages, it is useful to look at the overall characteristics of college and university library Web pages. Several studies have examined library institutional home pages. Laurel A. Clyde analyzed library home pages based on a survey of Nordic libraries and a content analysis of fifty public and fifty school libraries in thirteen countries. ${ }^{3}$ The most common features that library home pages exhibited were: the library's name; information about the library; links to selected Internet resources; an e-mail contact link; the address of the library; and links to resources about the local area or region. This research showed that in many libraries' Web sites, the target audience was unclear.

Stover and Zink evaluated randomly selected university and college library home pages found in an Internet directory. ${ }^{4}$ The authors ranked each page based on established criteria. The overall quality of the Web sites was found to be mediocre. One of the most common problems was that sites presented too many links and/or graphics, which led to disorganization and increased load time for those with slower modems. Also, of the forty sites examined, only two of the pages contained a statement of purpose.

David L. King took Stover and Zinks's research further. ${ }^{5}$ Without making any judgments of quality, he examined the home page design of all 120 ARL libraries in order to discover what the typical ARL library home page looked like. His results indicated that the typical library Web site was approximately one page in length and was usually only one to two steps from the parent institution's page. About half of the sites used background images or color. The document header usually contained the name of the library, and the document footer usually contained the name of the Web master and some form of contact information (usually an e-mail link). Most pages included some form of simple graphics, such as page dividers or buttons; and most included text-based hypertext links as well as unlinked text.

\section{Quality Considerations}

Addressing the quality issue, information scientists Helen C. Strain and Pauline M. Berry examined the literature related to Internet navigation problems and how human-computer interaction models can be applied to hypertext design. ${ }^{6}$ They proposed two areas of consideration for Web page design: "a good 
design model and good hypertext practice." ${ }^{7}$ The design model should have a clear purpose and regard the users and their needs. The hypertext design should consider how and what links are provided, should provide a coherent site structure, should include meaningful page titles, and should give a clear indication of the page origin. The authors conclude with a set of guidelines for Web page designers based on these areas.

In Building the Service-based Library Web Site, Kristen L. Garlock and Sherry Piontek discussed the importance of identifying a target audience for one's Web site. ${ }^{8}$ The authors made recommendations for good Web design to ensure clarity for the target audience. These included limiting the number of images on a site, using alternative text for images, avoiding browser-specific tags, annotating links to other sites, periodically checking for broken links, checking grammar and spelling, including an email link for feedback, and including the library's name in the title.

\section{Establishing Web Page Guidelines}

Several authors have published Web guidelines for universities and university libraries. Yale has posted a set of open, conceptual university guidelines for its Web site. ${ }^{9}$ The guidelines are organized into four sections (General Principles, Applications, Documents, and Pages) with links to examples throughout. The "General Principles" section reflects the conclusions drawn by Strain and Berry. This section recommends defining a purpose, paying attention to users and their needs, and identifying the page source. The principles also address the need to use HTML in a form that can be interpreted in both present and future contexts. Also at Yale, the Yale C/AIM Web Style Guide by Patrick J. Lynch and Sarah Horton provides a very practical style guide that concretely emphasizes the concepts outlined in the Guide for WEB Providers at Yale. ${ }^{10}$

Nancy McClements and Cheryl Becker discussed the steps involved in setting up the Web guidelines for the University of Wisconsin-Madison Campus Libraries. ${ }^{11}$ They studied current Web standards and other publications dealing with Web design to develop a set of very straightforward guidelines. Authors of any new Web pages originating from the University of Wisconsin-Madison Campus, personal or otherwise, are required to follow these standards if they want to link to the main library Web page. As with Yale, these guidelines include identification of the source of the page, including page author, and link to the parent home page. The guidelines also require the author to devise a plan for page revisions and to post the date last updated on the page. The use of standardized HTML also is required.

\section{Summary}

Although academic librarians' personal Web pages have not been the focus of any systematic study, the research of personal Web pages in general and the Web pages of universities and libraries in particular creates a starting point for investigation. Clearly, the focus of discussion has centered on communication and the necessity of defining the purpose and identifying the audience of a Web page. In the investigation described in the following sections, the author surveys librarians who have produced personal Web pages and evaluates the design and content of these sites. In addition, the author includes an examination of how institutional support and guidelines affect the overall quality of these Web pages.

\section{Methodology Population Surveyed}

The survey was conducted via e-mail. The survey questionnaire was sent to academic librarians' Web pages identified via two Internet directories of librarians web pages. These directories were publicly available at the time of the survey, however, they have since been discontinued. Respondents were sent surveys only if (1) their pages were in an educational domain (i.e., contained an edu, ca, or uk suffix), (2) the Web site be- 
longed to an academic librarian, and (3) the site had an e-mail address listed. Although the librarians selected were not anonymous to the researcher, all responses were kept confidential. The survey was conducted between October and December 1997. Participation was voluntary, and no follow-up letters were sent.

\section{Development of Questionnaire and Checklist}

A small semi-structured pilot survey was conducted prior to the final survey to get a sense of the range of possible answers to various questions. The final survey contained multiple-choice questions dealing with how and why the Web site was created, how the site was maintained, what training and guidelines were given to the site-creator, and the purposes of the page.

Following the survey, the researcher filled out a checklist for each of the respondents to determine information about the Web sites that was not apparent from the survey responses. Given that previous researchers found an overall mediocre quality to library Web sites and have focused efforts on improving this (see Clyde, ${ }^{12}$ Jonathan Furner-Hines and Peter Willet, ${ }^{13}$ and Stover and Zink $^{14}$ ), the checklist was constructed based on quality considerations and was designed to assess the types of information each site provided and how the site was constructed.

\section{Results}

\section{Response Rate}

Of the ninety-two e-mail questionnaires sent out, fifty-nine were returned for a response rate of 64.1 percent. Eight were disqualified because either they did not fit the criteria of the study or their URL changed during the course of the study. Given that no follow-up letter was sent, this was a relatively high rate of return. Earlier research gave somewhat conflicting data on the effectiveness of e-mail surveys (see Lee S. Sproull, ${ }^{15}$ Randall L. Sell, ${ }^{16}$ and Susan E. Anderson and Bruce M. Gansneder ${ }^{17}$ ). However, given the convenience of this type of survey for subjects in comparison to other survey types such as telephone and mail (e.g., respondents could complete the survey at their leisure, did not have to leave their office to find a mailbox, etc.), the high rate of return is understandable.

\section{Purpose of Librarian's Personal Web Pages}

The first set of survey questions dealt with the creation of the Web pages themselves. An overwhelming 82.4 percent of respondents indicated that they created their pages voluntarily or on their own personal initiative. An even higher percentage $(92.0 \%, \mathrm{~N}=51)$ did the HTML coding for their pages themselves, and all of the respondents provided the content for the sites themselves. It is clear from the data that the majority of the librarians produced their Web pages as a service to their library's patronage. Of the librarians surveyed, most indicated faculty, students, and staff as the target audience for their Web sites. The qualitative analysis of the Web sites indicated that the majority provided professional information about the librarian $(94.1 \%$, $\mathrm{N}=51)$, the library $(76.5 \%, \mathrm{~N}=51)$, and the parent institution $(84.3 \%, \mathrm{~N}=51)$. Librarians themselves indicated that they believed people use their Web sites for various reasons, such as to find information about them $(58.0 \%, \mathrm{~N}=50)$, to find information on their subject specialties $(50.0 \%, \mathrm{~N}=50)$, and to find information about the library or institution $(42.0 \%, \mathrm{~N}$ $=50$ ). Although many were unsure of how often others used their Web sites $(35.3 \%, N=51)$, many believed that their sites were accessed by others daily $(31.4 \%, \mathrm{~N}=51)$ or more than once a week $(23.5 \%, \mathrm{~N}=51)$. Less than ten percent believed that others accessed their sites less than once a week.

Librarians also made use of their own Web sites. Survey data showed that 39.2 percent $(\mathrm{N}=51)$ of librarians accessed their own sites daily, whereas 21.6 percent $(\mathrm{N}=51)$ visited their own sites more than once a week. Most indicated that 
they used their sites for jobrelated reasons $(70.0 \%, \mathrm{~N}=$ $50)$. Given that most of these sites were created on personal initiative, it is not surprising that a large number of librarians $(46.0 \%, \mathrm{~N}=50)$ also used their sites for avocational reasons.

\section{Training and Support Issues}

Although the majority of these personal Web pages clearly benefit their respective libraries, many of the libraries or parent institutions failed to provide adequate training and support for the librarians producing the Web pages. Only 10.3 percent $(\mathrm{N}=39)$ of the respondents felt that they received more than adequate training and support. Moreover, although 38.5 percent $(\mathrm{N}=39)$ felt that they had received adequate training and support, a nearly equal 35.9 percent $(\mathrm{N}=39)$ had been given no institutional training or support and 15.4 percent $(\mathrm{N}=39)$ felt that their training or support had been inadequate.

Table 1 indicates the types of training that page-creators received from both their institutions and other sources. Entries in table I are the percentages of respondents (from a total of $\mathrm{N}=51$ for In-

\section{TABLE 1}

Types of Training Provided by Institutions and Other Sources, in Percentages

\begin{tabular}{lrc} 
Type of Training & Institution & Other Sources \\
\hline Written documentation & 23.5 & 38.8 \\
Computer tutorial & 2.0 & 14.3 \\
Workshop & 37.3 & 20.4 \\
One-on-one & 15.7 & 10.2 \\
Other & 15.7 & 16.3
\end{tabular}

stitution and $\mathrm{N}=49$ for Other Sources) receiving each type of training. These percentages need not add up to 100 percent. Institutionally, the most highly employed type of training was the workshop, whereas individually the types of training were more varied.

Related to the issue of support and training, only 42.9 percent $(\mathrm{N}=49)$ of the respondents indicated that they had been provided with a list of requirements and/or guidelines for creating personal Web pages. Table 2 indicates the specific guideline criteria that were provided to those respondents who received them.

\section{Quality of Librarian's Personal Web Pages}

In lieu of the absence of consistent support, training, and guidance, it is not surprising that the qualitative analysis of the Web page characteristics revealed some inadequacies. Although research indicates that a clear purpose is the most highly recommended feature of a Web site, only 56.9 percent $(\mathrm{N}=51)$ of the pages had either a clearly stated purpose or one that could easily be inferred from the content.

In general, however, the pages examined had two major purposes: (1) to serve as a self-promotion tool in the form of an online resume or business card; and (2) to provide links to sites 
in a particular subject area. The sites with unclear purposes tended to serve both of these purposes as well as to include links and information relating to entertainment in a variety of areas, family members and friends, and Internet help.

With respect to HTML coding, few sites provided alternate text for most images $(22.9 \%, \mathrm{~N}=48)$ or had an HTML-coded title that truly reflected the content of the page $(29.4 \%, \mathrm{~N}=51)$. When scoring pages on whether the title reflected the content of the Web site, the rule established was that any individual bookmarking the site must be able to understand the contents of the site from the title. Contents should not simply be a reflection of who created the site, but also should indicate what the site contained in terms of information. Thus, sites that were titled in the format "Jane Doe's Home Page" were considered not to have a title that reflected the content of the page because one would have to know Jane Doe in order to make sense of the title. Conversely, a site in the format "Jane Doe, Acquisitions Librarian, XYZ University" would be considered to have a title that reflected the content of the page. Only 39.2 percent $(\mathrm{N}=51)$ used META data in the HTML coding, even though this is a key issue of concern in the library world today (see Dublin Core Resource Page http://purl.ococ.org/ metadata/dublin_core ${ }^{18}$ ).

\section{Some of the librarians surveyed indicated a certain amount of hostility, or at least passive resis- tance, to institutional control over the content of their personal Web pages.}

Consistent with King's findings regarding ARL Library Web pages, the majority of the personal Web Sites provided information about the parent institution; however, only little more than half of the sites provided links to the parent institution $(58.8 \%, \mathrm{~N}=50)$ or the parent library's Web page $(58.0 \%, \mathrm{~N}=51) .{ }^{19}$ Thus, many librarians missed an oppor- tunity to benefit their own institutions by neglecting to take full advantage of one of the Web's greatest assets: the ability to create hypertext links between sites.

On the positive side, most Web sites were updated less than six months prior to the evaluation $(89.8 \%, \mathrm{~N}=49)$ and showed consistency in style within internal site links (77. 1\%, $\mathrm{N}=35)$. However, very few exhibited any consistency in style, such as page layout, colors used, etc., to the parent library's Web site (17.1 $\%, \mathrm{~N}=49$ ).

An independent t-test was run on the data to see if librarians who had been provided with guidelines had overall betterquality Web pages. The mean score of qualitative page characteristics was used to determine overall quality. The qualitative page characteristics used to calculate this mean were: professional content; identification and links to the parent library and institution; statement of purpose; meaningfulness of page title; number of dead links; currency; use of ALT text; use of META data; consistency of style; and size of images. The test was significant $(t=-2.31, p=.025)$. Librarians who had been given guidelines $(M=.67$, $S D_{-}=.16 ; \mathrm{N}=21$ ) had better-quality personal Web pages than those who had not been given guidelines $(M=.58, S D=.11$; $\mathrm{N}=28$ ).

\section{Conclusion}

Although academic librarians' personal Web pages exist for different purposes, overall they provide an extension to the library's institutional Web page. Their role includes providing information about the library and providing links to selected resources.

Librarians' accomplishments with regard to their personal Web pages are to be praised considering that many librarians are working with limited amounts of time and resources. As an integral part of the virtual library, however, there is room for improvement. Based on this research, as well as on recommendations made by previous researchers, these Web 
pages could be perfected by better focusing on a target audience, making titles more informative, clearly identifying and linking to the parent library and institution, using ALT tags more thoroughly, and including META data.

There is some concern, however, that too many restrictions will inhibit creativity and motivation. Some of the librarians surveyed indicated a certain amount of hostility, or at least passive resistance, to institutional control over the content of their personal Web pages. For example, one respondent remarked: "I belong to the school that holds that every librarian should have ... relatively unfettered freedom to mount and maintain sites in their subject specialties, without having to go through the regulatory bottlenecks. I know [a librarian] who has basically given up on maintaining a site because she can never get her updates mounted at all." Perhaps due to the frustration with institutional bureaucracy, some librarians indicated that they have an "official" personal home page that follows the guidelines of their institution and an "unofficial" page. (Interestingly, these "unofficial" pages were located on the university server.) In his article entitled "Web Policies That Work," Michael Stoner points out to university Web policy creators: "You want to ensure that your institution's official Web pages are well-designed, accurate, and in compliance with state and federal laws. But you must also avoid stifling the creativity of those who want to experiment with this exciting medium." 20

As this research shows, library and/ or institutional guidelines significantly affect the quality of page design. By providing support and instruction, institutions can further help librarians who may have difficulty finding the time or money to seek outside training. Recently, Cherrie Noble, in her article titled "Reflecting on Our Future: What Will the Role of the Virtual Librarian Be?" expressed her thoughts on the importance of continuing education for librarians. She stated: "Staff training and professional development for librarians are fundamental in developing the virtual library ... This is a critical issue for librarians, and one that we will need to work on vigorously in the coming years, in an attempt to meet, and hopefully exceed, the expectations of our patrons." ${ }^{21}$ Ultimately, it will be up to each individual librarian to make a professional commitment to learn the skills required to produce an effective a Web page. In the future, as academic librarians continue to create personal Web pages, it will also be important to look at how the role of these pages change over time as new policies are enacted and the Internet evolves.

\section{Notes}

1. Mark Stover and Steven D. Zink, "World Wide Web Home Page Design: Patterns and Anomalies of Higher Education Library Home Pages," Reference Services Review 24 (fall 1996): 15.

2. Marcia J. Bates and Shaojun Lu, "An Exploratory Profile of Personal Home Pages: Content, Design, Metaphors," Online E CDROM Review 21 (Dec. 1997): 331-40.

3. Laurel A. Clyde, "The Library as Information Provider: The Home Page," Electronic Library 14 (Dec. 1996): 549-58.

4. Stover and Zink, "World Wide Web Home Page Design," 7-20.

5. David L. King, "Library Home Page Design: A Comparison of Page Layout for Front-ends to ARL Library Web Sites," College E Research Libraries 59 (Sept. 1998): 458-65.

6. Helen C. Strain and Pauline M. Berry, "Better Page Design for the World Wide Web," Online and CDROM Review 20, no. 5 (Oct. 1996): 227-38.

7. Ibid., 233.

8. Kristen L. Garlock and Sherry Piontek, Building the Service-based Library Web Site: A Step-by-Step Guide to Design and Options (Chicago: ALA, 1996). 
9. Yale University, Guide for WEB Providers at Yale, [Online] 1995. Available at <http:// www.cis.yale.edu/webguide/>.

10. Patrick J. Lynch and Sarah Horton, Yale C/AIM Web Style Guide, Yale Center for Advanced Instructional Media. [Online] 1997. Available at <http://www.komm.ruc.dk/ interkomm/manual/index.html .

11. Nancy McClements and Cheryl Becker, "Writing Web Page Standards," College E Research Libraries News 1 (Jan. 1996): 16-17. Also found in Electronic Library Access Committee (ELAC), User Documentation Working Group, UW-Madison Campus Libraries Web Page Standards and Guidelines. [Online] December 4, 1997. Available at http://www.library.wisc.edu/ help/tech/Web_standards.html>.

12. Clyde, "The Library as Information Provider," 549-58.

13. Jonathan Furner-Hines and Peter Willett, "The Use of the World-Wide Web in UK Academic Libraries," Aslib Proceedings 47 (Jan. 1995): 23-32.

14. Stover and Zink, "World Wide Web Home Page Design," 7-20.

15. Lee S. Sproull, "Using Electronic Mail for Data Collection in Organizational Research," Academy of Management Journal 29 (Mar. 1986): 163.

16. Randall L. Sell, "Research and the Internet: An E-mail Survey of Sexual Orientation," American Journal of Public Health 87 (Feb. 1997): 297.

17. Susan E. Anderson and Bruce M. Gansneder, "Using Electronic Mail Surveys and Computer-Monitored Data for Studying Computer-Mediated Communication Systems," Social Science Computer Review 13 (spring 1995): 40.

18. Dublin Core Metadata Initiative. Dublin Core. [Online] 1998. Available at <http:// purl.oclc.org/dc/>.

19. King, "Library Home Page Design," 460.

20. Michael Stoner, "Web Policies That Work," Case Currents 21 (Oct. 1995): 37.

21. Cherrie Noble, "Reflecting On Our Future," Computers in Libraries 18 (Feb. 1998): 52. 